\title{
FACTORS AFFECTING DECISION-MAKING IN OUTSOURCING HEALTH SERVICES USING A STRUCTURAL EQUATION MODELING APPROACH
}

\author{
Morteza Nazari1 , Leila Riahi², Seied Jamaleddin Tabibi3i, Mahmoud Mahmoudi Majdabadi Farahani ${ }^{4}$
}

1Ph. D Student of Health Services Management, Science and Research Branch, Islamic Azad University, Tehran, Iran.

${ }^{2}$ Assistant Professor, Department of Health Services Management, Science and Research branch, Islamic Azad University, Tehran, Iran.

3 Professor, Department of Health Services Management, Science and Research Branch, Islamic Azad University, Tehran, Iran.

${ }^{4}$ Professor, Department of Health Services Management, Science and Research branch, Islamic Azad University, Tehran, Iran.

\section{ABSTRACT}

\section{BACKGROUND}

In developing countries, the restructuring of financial resources is one of the components of the health system reform policy. In this regard, outsourcing services is one of the types of interventions that is under consideration. The purpose of this research is to develop a decision-making model for outsourcing services in Iranian public hospitals.

\section{METHODS}

This is an exploratory study. For data analysis, the statistical methods of exploratory and deterministic analysis were used with IBM SPSS Statistics 23 and LISREL 8.8 software.

\section{RESULTS}

Effective factors in deciding on outsourcing services in Iran's public hospitals include economic factors with a load factor of $0 / 70$, characteristics of service with a load factor of $0 / 60$, environmental factors with a load factor of $0 / 46$, social factors with a load factor of $0 / 42$, and resource with a load factor of $0 / 40$. Standardized load factor values and T values for significant loading factors' tests indicate that all extracted factors are significant in outsourcing measurements in comparison with $\mathrm{T}$ values $(\mathrm{p}<0.001, \mathrm{~T}>2)$.

\section{CONCLUSIONS}

The proposed model for decision making outsourcing services in Iranian public hospitals in the form of a comprehensive and multidimensional concept consists of six effective factors (economic, service, environment, policy, social, and resources). Therefore, consideration of all aspects of its components can lead to the successful outsourcing of services in the public hospitals to achieve the desired goals.

\section{KEY WORDS}

Decision Making, Economics, Hospitals, Outsourced Services

HOW TO CITE THIS ARTICLE: Nazari M, Riahi L, Tabibi SJ, et al. Factors affecting decision-making in outsourcing health services using a structural equation modeling approach. J. Evolution Med. Dent. Sci. 2019;8(27):2137-2143, DOI: $10.14260 /$ jemds/2019/469

\section{BACKGROUND}

The public sector as a health service provider in many countries faces many challenges that reduces its effectiveness. One of the main solutions to the health system's problems is the outsourcing of various services to the private sector.[1,2] Currently, assignment of health services as an important issue and cost-effectiveness solution is discussed in many countries around the world.[3,4]

The transfer of organs in industrialized countries did not include the health sector, but it is currently a good model for health sector providers. The deployment of health care services in advanced countries expanded in the middle of the $90 \mathrm{~s},[5]$ and recently outsourcing of services has been increasingly proposed as a tool to increase the success, effectiveness, and efficiency of health services.[2,6]

\section{'Financial or Other Competing Interest': None.}

Submission 19-02-2019, Peer Review 22-06-2019,

Acceptance 28-06-2019, Published 08-07-2019.

Corresponding Author:

Leila Riahi,

Department of Health Services Management,

Science and Research branch,

Islamic Azad University, Tehran, Iran

E-mail: l.riahi@srbiau.ac.ir

DOI: $10.14260 /$ jemds $/ 2019 / 469$
Outsourcing of government hospitals began with noncore sectors and support services, but clinical services such as outpatient surgeries, labs, and imaging are now included in this area. ${ }^{[7]}$

The researches show that half of the outsourcing contracts fail due to failure of performance of pre-assignment analysis and not being able to reach the pre-set goals. ${ }^{[7,8]}$ For instance, in a study that was done by Jamal Bata in US. Public hospitals, he determined some consequences such as conflicts between stakeholders and beneficiaries, increased coordination costs, poor monitoring, and control and outsourcing of core competencies of hospitals as the negative outcomes of some changes. ${ }^{[9]}$ Also, in the research that was done in 2015 in the hospitals of Tehran University of Medical Sciences, it was found that outsourcing policy due to the lack of proper pattern of the assignment and the weakness of government management has not been achieved to selfregulation goals, including the minimizing the structure of the health system and improving performance. ${ }^{[10]}$

In a study conducted by Donnie and Polak to examine the effects of the transfer of therapeutic sections to private sector, it was found that the participation of the community and the private sector, although with the aim of enabling service delivering, reduced the rate of admission and income in various specialties in Scottish hospitals.[11] In Maysler's research, conducted during his research in 2004, he noted the 
lack of outsourcing decision making process before assignment as a major factor in the failure of the private sector's service delivery strategy.[12] The organization's decision to outsource certain sectors and perform some activities by itself is the perfect way to get out of the challenges of outsourcing and to succeed in its strategy. [7,9,13]

The issue that senior executives are faced with is not the use of outsourcing, but a service that needs to be outsourced, and this requires that outsourcing strategies be clearly identified. Therefore, decisions for outsourcing are issues that are affected by various and contradictory factors. This implies the use of systematic decision-making tools more than ever, methods that enable the decision maker to determine the definite priorities of choices.[14] A study by McIvor on the successful factors of the studies showed that by using outsourcing decision-making models, flexibility, customer service and core competencies can be enhanced.[15]

The importance of this research topic, as well as the lack of a decision-making model for outsourcing services in the public hospitals in Iran, led the researcher to study the related theory and analysis of results, to find a model of effective factors for outsourcing services in Iranian public hospitals.

\section{METHODS}

\section{Design and Subject}

This research in terms of results is among applied studies, exploratory in terms of purpose of the research and this crossed-sectional study was conducted at Iranian Public Hospitals in 2018. The study duration took 6 months starting from January 10, 2018 to June 10, 2018. Quantitative and qualitative methods have been used in different stages of the research. Finally, a decision model has been developed for outsourcing services in the state hospitals of the country.

\section{Sample Size Calculation}

Although, there isn't any general agreement about the size of the samples needed for factor analysis and models of structural equations; however, this size should be at least 200 samples based on the recent researchers. Therefore, the sample size in the methodology of structural equation modeling can be determined between 5 - 15 observations versus any measured variables. $5 \mathrm{q} \leq \mathrm{n} \leq 15 \mathrm{q}$

Where $\mathrm{n}$ is sample size and $\mathrm{q}$ is number of variables in the questionnaire [16] Considering that the exploratory factor analysis was used in data analysis, for the purpose of obtaining reliable results, 400 samples were identified.

\section{Data Collection}

We have used a questionnaire containing 65 questions for collecting data that its variables are derived from comparative studies, its validity has been evaluated by experts and in particular its reliability is determined by the Cronbach's alpha coefficient of 0.92. Questions of the questionnaire have been evaluated with five-point choices of Likert scale in a way that the lowest in terms of importance has got the score of 1 and the most important one is given 5 points. At the end of the questionnaire, an annotated question was asked to provide suggestions on the removal of some research questions or adding questions. Statistical populations consist of the members of the scientific board of universities, health system policy-makers, experts in outsourcing and government hospital directors. Stratified random sampling was used for sampling. After of distributing 400 questionnaires, 376 completed questionnaires were collected.

\section{Ethical Statements}

The project proposal was approved by the ethical committee of Alborz University of Medical Sciences (Ethical code of project: Abzums.Rec.1396.210). After the study objectives had been explained, oral consent was obtained from participants at each session.

\section{Statistical Analysis}

By using exploratory factor analysis, the factors affecting the outsourcing of hospital services were identified and extracted. In exploratory factor analysis, we used the varimax rotation technique and principal components analysis method for factor identification. In the following, factors are confirmed and evaluated using the confirmatory factor analysis of the extracted factors. Data analysis was performed using IBM SPSS Statistics 23 and LISREL 8.8 software-(USA). Due to the orderly distribution of outsourcing items, the least squares weighting method has been used in the confirmatory factor analysis to calculate the parameters and evaluate the conceptual model.

\section{RESULTS}

\section{Describing Demographic Variables of The Sample Study}

Table 1 shows the frequently distribution of samples presented in this study according to gender, age, job status, level of education and work experience. According to the results 58/5\% were women and the rest were men. Most of them were between the ages 31-40 (55/3\%). Out of them, 48 persons $(12 / 8 \%)$ were managers of hospitals. $64 / 9 \%$ had undergraduate and $47 / 9 \%$ had work experience of $11-20$ years.

\section{Exploratory Factor Analysis to Determine the Effective Factors in Outsourcing of Hospital Services}

In determining the effective factors in the outsourcing of hospital services, out of 65 variables affecting the outsourcing of hospital services, which were based on the study of texts and opinions of professors and experts, 7 items due to the similarity of the concept and high correlation with other items in the questionnaire were deleted. Out of 57 items, 12 items were deleted due to a load factor of less than 0.5 and also lack of interpretability in agents according to experts' ideas. According to the gravel chart (Figure 1), after the sixth factor, the gradient of the graph was almost horizontal, and the addition of the seventh factor did not have much effect on the increase of variance, and based on the special value greater than 2 (Figure 1) and the results of exploratory factor analysis to determine the factors affecting outsourcing, the effective variables in outsourcing were classified in 6 interpretable factors and were identified from 46 variables. The total explained variance based on 6 factors was equal to $62.5 \%$. The KMO index of $\mathrm{K} 2=0.692$ indicates that the sample size is sufficient for factor analysis. Also, the value of $p$ $0.001<\mathrm{p}$ (chi-square $=23590$ and DF $=1035$ ) in the Bartlett test confirms the condition of the spheroid in the factor analysis. 


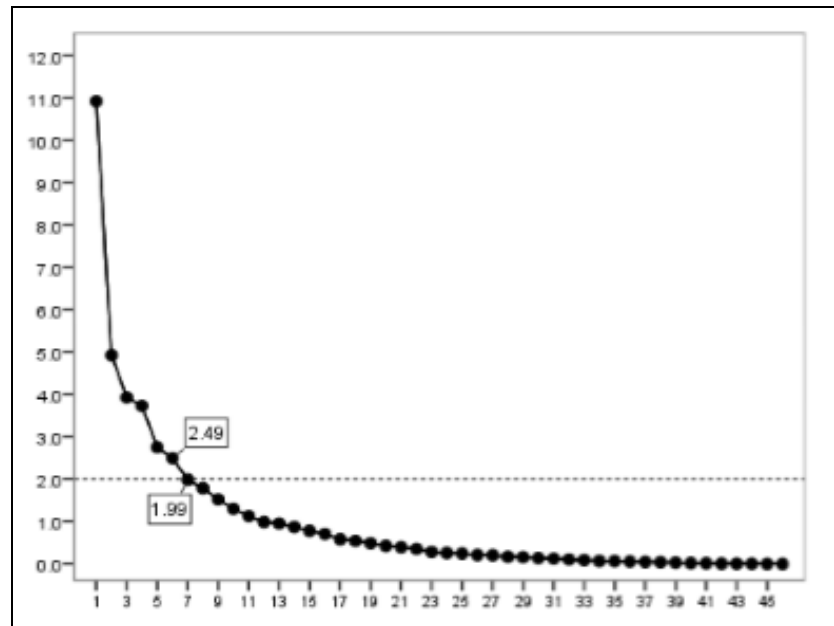

Figure 1. Pebble Chart to Identify the Number of Effective Factors in Outsourcing Based on Factor Analysis

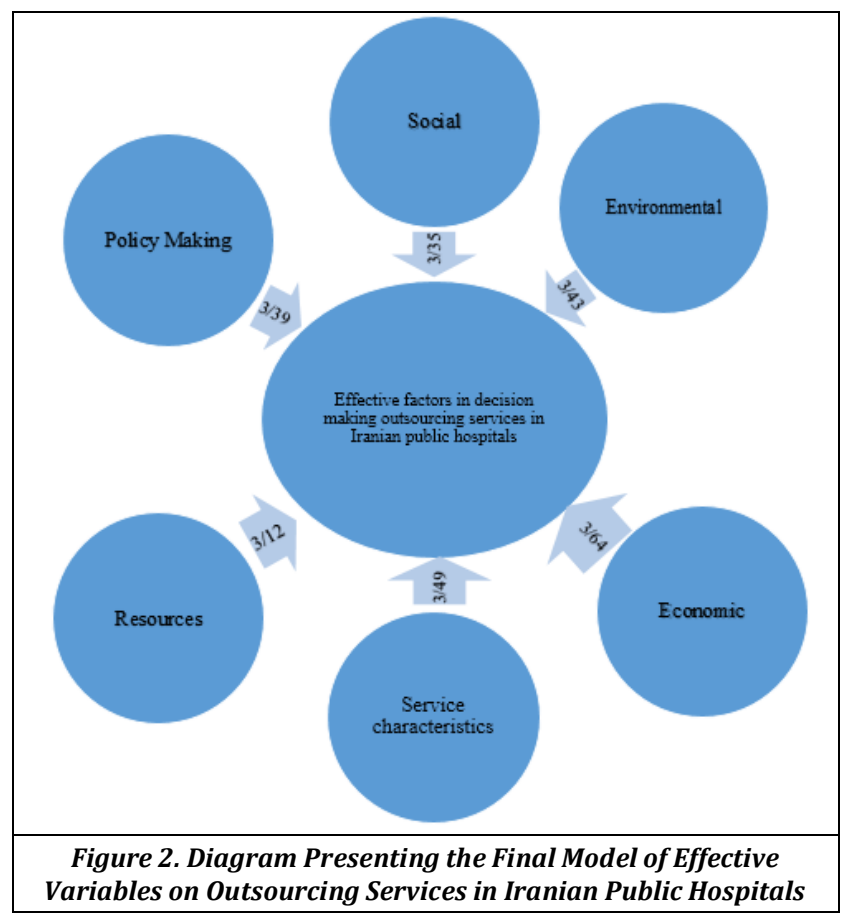

\begin{tabular}{|c|c|c|c|}
\hline Variable & Group & Frequency & Percentage \\
\hline \multirow{2}{*}{ Gender } & Female & 220 & $58 / 5$ \\
\hline & Male & 156 & $41 / 5$ \\
\hline \multirow{5}{*}{ Age } & Less than 30 & 56 & $14 / 9$ \\
\hline & $31-40$ & 208 & $55 / 3$ \\
\hline & $41-50$ & 84 & $22 / 3$ \\
\hline & $51-60$ & 20 & $5 / 3$ \\
\hline & More than 60 & 8 & $2 / 1$ \\
\hline \multirow{4}{*}{ Job } & Headquarters & 84 & $22 / 3$ \\
\hline & Manager & 48 & $12 / 8$ \\
\hline & Hospital expert & 56 & $14 / 9$ \\
\hline & other & 188 & 50 \\
\hline \multirow{4}{*}{ Education } & Undergraduate & 244 & $64 / 9$ \\
\hline & Senior grade & 104 & $27 / 7$ \\
\hline & MD & 16 & $3 / 4$ \\
\hline & PhD & 12 & $3 / 2$ \\
\hline \multirow{5}{*}{ Work experience } & Less than 10 & 124 & 33 \\
\hline & $11-20$ & 180 & $47 / 9$ \\
\hline & $21-30$ & 64 & 17 \\
\hline & More than 30 & 8 & $2 / 1$ \\
\hline & Total & 376 & 100 \\
\hline \multicolumn{4}{|c|}{$\begin{array}{c}\text { Table I. Frequency Distribution and Percentage of Demographic } \\
\text { Variables in the Subjects }(n=376)\end{array}$} \\
\hline
\end{tabular}

\begin{tabular}{|c|c|c|c|c|c|}
\hline Factors & Items & Number & Mean & Median & Alpha \\
\hline Resources & $6-22$ & 17 & $0.79 \pm 3.12$ & 3.18 & 0.93 \\
\hline Economic & $23-30$ & 8 & $0.18 \pm 3.64$ & 3.75 & 0.90 \\
\hline Service feature & $1-5$ & 5 & $0.84 \pm 3.49$ & 3.60 & 0.85 \\
\hline Social & $41-46$ & 6 & $0.78 \pm 3.35$ & 3.35 & 0.80 \\
\hline Environmental & $36-40$ & 5 & $0.79 \pm 3.43$ & 3.40 & 0.79 \\
\hline Policy making & $31-35$ & 5 & $0.80 \pm 3.39$ & 3.40 & 0.82 \\
\hline \multicolumn{7}{|c|}{ Total } & $1-46$ & 46 & $0.50 \pm 3.34$ & 3.38 & 0.92 \\
\hline Table 2. Outsourcing Factors Extracted from Exploratory Factor \\
Analysis and Reliability of Effective Factors on Outsourcing \\
\hline \multicolumn{7}{|c|}{ \#Cronbach's alpha } \\
\hline
\end{tabular}

\begin{tabular}{|c|c|c|c|}
\hline $\begin{array}{c}\text { Fit } \\
\text { Indices }\end{array}$ & Complete Name & $\begin{array}{c}\text { Acceptable } \\
\text { Level }\end{array}$ & $\begin{array}{c}\text { Value in } \\
\text { Model CFA }\end{array}$ \\
\hline$\chi^{2}$ & Chi Square & - & $3027 / 20$ \\
\hline DF & Degree of Freedom & - & 975 \\
\hline$\frac{\chi^{2}}{\mathrm{DF}}$ & Chi-Square to DF & $<4$ & $3 / 10$ \\
\hline RMSEA & $\begin{array}{c}\text { Root of Mean Square Error } \\
\text { Approximation }\end{array}$ & $<0.08$ & 0.065 \\
\hline SRMR & Standardized Root Mean Residuals & $<0 / 10$ & $0 / 071$ \\
\hline GFI & Goodness of Fit Index & $>0 / 90$ & $0 / 96$ \\
\hline CFI & Comparative Fit Index & $>0 / 90$ & $0 / 93$ \\
\hline NFI & Normed Fit Index & $>0 / 90$ & $0 / 91$ \\
\hline IFI & Incremental Fit Index & $>0 / 90$ & $0 / 95$ \\
\hline TLI & Tucker-Lewis Index & $>0 / 90$ & $0 / 90$ \\
\hline \multicolumn{2}{|c|}{ Table 3. CFA Model Fitness Indices and Acceptable Level of its } \\
\hline \multicolumn{4}{|c|}{ Indices } \\
\hline
\end{tabular}

Outsourcing Factors Extracted from Exploratory Factor Analysis and Reliability of Effective Factors on Outsourcing

These factors that are extracted from factor and average analysis, standard deviation as well as the reliability of extracted factors are shown in table 2 . Also, in order to avoid overcrowding of the table, the easier interpretation and the ineffectiveness of low factor loads, the factor loaded below 0.5 are not shown.

Confirmatory Factor Analysis to Evaluate and Test the Effective Factors in Outsourcing of Hospital Services The values of the standardized load factor for the significance test of factor loads indicate that all items have a large enough load of factor with respect to the values of $2<\mathrm{T}$, all factor loads in measuring outsourcing factors are significant. The fitting index values of table- 3 show the appropriate fit of the model and confirm the conceptual model for outsourcing agents with 46 items and 6 factors.

6 Factors Included in Final Model after Exploratory and Confirmatory Factor Analysis

- Economic.

- Service characteristics.

- Environmental.

- Policy making.

- Resources.

- Social. 


\begin{tabular}{|c|c|c|c|c|c|c|c|}
\hline No. & Effective Items in Outsourcing the Health Services & Resources & Economic & $\begin{array}{c}\text { Service } \\
\text { Characteristics }\end{array}$ & Social & Environmental & \begin{tabular}{|c|} 
Policy \\
Making
\end{tabular} \\
\hline 1 & $\begin{array}{l}\text { Outsourcing of services not included in the main activities of } \\
\text { the hospital }\end{array}$ & & & 0.79 & & & \\
\hline 2 & $\begin{array}{l}\text { Separability analysis of services available from other hospital } \\
\text { services }\end{array}$ & & & 0.89 & & & \\
\hline 3 & Verification of the services to be outsourced & & & 0.88 & & & \\
\hline 4 & Pay attention to the complexity of the services to be assigned & & & 0.54 & & & \\
\hline 5 & $\begin{array}{l}\text { The existence of technical knowledge in relation to activities } \\
\text { in the organization }\end{array}$ & & & 0.60 & & & \\
\hline 6 & $\begin{array}{c}\begin{array}{c}\text { Enhancing flexibility of the organization against } \\
\text { environmental variables }\end{array} \\
\end{array}$ & 0.63 & & & & & \\
\hline 7 & \begin{tabular}{|c|} 
Focus on improving the quality of service delivery to service \\
recipients
\end{tabular} & 0.69 & & & & & \\
\hline 8 & Increasing the capacity to use internal organization resources & 0.56 & & & & & \\
\hline 9 & $\begin{array}{c}\text { Improving the organization's ability to manage equipment } \\
\text { and technology }\end{array}$ & 0.65 & & & & & \\
\hline 10 & $\begin{array}{l}\text { Release of resources of the organization, including manpower } \\
\text { and equipment }\end{array}$ & 0.76 & & & & & \\
\hline 11 & More monitoring and control over organization activities & 0.70 & & & & & \\
\hline 12 & $\begin{array}{l}\text { Having a specific program for moderated forces as a result of } \\
\text { outsourcing }\end{array}$ & 0.59 & & & & & \\
\hline 13 & Investigating qualified contractors in the field of outsourcing & 0.57 & & & & & \\
\hline 14 & Examining laws for labour unions & 0.73 & & & & & \\
\hline 15 & Sharing the risk between the organization and the supplier & 0.79 & & & & & \\
\hline 16 & Development of cooperation with other hospitals & 0.58 & & & & & \\
\hline 17 & Pay attention to the wide range of service providers & 0.74 & & & & & \\
\hline 18 & $\begin{array}{l}\text { INVESTIGATE of risk of dependency on suppliers and their } \\
\text { potential misuse }\end{array}$ & 0.69 & & & & & \\
\hline 19 & Achieving a competitive position over other hospitals & 0.65 & & & & & \\
\hline 20 & $\begin{array}{l}\text { pay attention to the performance of other hospitals in } \\
\text { outsourcing similar services }\end{array}$ & 0.70 & & & & & \\
\hline 21 & Existence of superior technologies in the outside of hospital & 0.69 & & & & & \\
\hline 22 & Attention to environmental standards & 0.61 & & & & & \\
\hline 23 & Cost and revenue analysis of outsourcing services & & 0.54 & & & & \\
\hline 24 & $\begin{array}{c}\text { Reduce organization costs (such as service and overhead } \\
\text { costs) }\end{array}$ & & 0.70 & & & & \\
\hline 25 & Creating additional resources & & 0.64 & & & & \\
\hline 26 & $\begin{array}{c}\text { Profitability generated through outsourcing activities for } \\
\text { organization }\end{array}$ & & 0.85 & & & & \\
\hline 27 & Increased investment & & 0.87 & & & & \\
\hline 28 & Improved productivity in service delivery & & 0.67 & & & & \\
\hline 29 & Cost analy sis and supplier price & & 0.74 & & & & \\
\hline 30 & increase revenue & & 0.77 & & & & \\
\hline 31 & The importance and relative sensitivity of activity & & & & & & 0.56 \\
\hline 32 & creating Innovation at the facility & & & & & & 0.63 \\
\hline 33 & $\begin{array}{l}\text { The need to comply with the instructions and regulations } \\
\text { issued regarding the outsourcing of services }\end{array}$ & & & & & & 0.77 \\
\hline 34 & Adaptation of hospital policies with assigning services & & & & & & 0.79 \\
\hline 35 & $\begin{array}{c}\text { The possibility of providing educational and research services } \\
\text { in the field of outsourced }\end{array}$ & & & & & & 0.68 \\
\hline 36 & Pass the risk and give it to the contractors & & & & & 0.77 & \\
\hline 37 & $\begin{array}{l}\text { the analysis of the risks caused by the inappropriate } \\
\text { providing of the service by the }\end{array}$ & & & & & 0.79 & \\
\hline 38 & Existence of government regulations on outsourcing & & & & & 0.61 & \\
\hline 39 & $\begin{array}{c}\text { Provincial authorities' political pressures to outsourcing some } \\
\text { services without conducting necessary inspections }\end{array}$ & & & & & 0.74 & \\
\hline 40 & $\begin{array}{l}\text { The insistence of the Ministry of Health officials to outsource } \\
\text { certain services without conducting the necessary } \\
\text { examinations }\end{array}$ & & & & & 0.58 & \\
\hline 41 & Focus on responding to changing needs of stakeholders & & & & 0.50 & & \\
\hline 42 & Focus on the access of middle and lower classes to services & & & & 0.50 & & \\
\hline 43 & Focus on satisfaction of patients and patients to the hospital & & & & 0.72 & & \\
\hline 44 & $\begin{array}{c}\text { Paying attention to the interests and wishes of stakeholders in } \\
\text { outsourcing services }\end{array}$ & & & & 0.80 & & \\
\hline 45 & Attract staff participation in outsourcing services & & & & 0.63 & & \\
\hline 46 & Hospital managers' view of outsourcing services & & & & 0.73 & & \\
\hline
\end{tabular}

\section{DISCUSSION}

Different organizations in respect of their policies and objectives, the nature of the product or service, and especially the position of the business environment use different levels of outsourcing. Some of them completely use external capabilities and the others rely on internal human and physical resources. The importance of using the right decision in this issue is due to the effects on the organization's performance.[17] The result of the research showed that the variables considered in decision pattern for Iranian public hospitals outsourcing services consist of concepts, which are categorized in 6 groups. These variables are discussed and interpreted further. 


\section{Economic Factor}

A survey of respondents' opinions about their variables showed that the variable "cost and revenue analysis of outsourcing services" with the factor load of 0.97 had the highest correlation and reliability among other types of economic factors, because the first goal of outsourcing services is to save costs and increase revenue. According to the theory of transaction costs and turnover, if the cost of doing activity by market resources is higher than the activities done within the organization, the activity should be done inside the organization.[18]

In support of this finding, the outcome of a study of Iki Diyashi in the country's hospitals in 2015, titled "important and influential factors in outsourcing decision-making in facility management (A case study in Nigerian state parliaments) is noteworthy. The data of the research were collected from 74 public hospitals by using questionnaires containing 65 questions which were distributed among managers and hospitals' staff. After analysing, 6 important factors were extracted by using exploratory factor analysis method and introduced "cost and revenue analysis before services" as the most important factor in outsourcing services in the country's public hospitals.[19]

Also, it is mentioned in another research titled "outsourcing to state hospitals of Greece" which was done in 100 public hospitals in Greece that saving costs, customer satisfaction, and focusing on key issues are considered as important factors in the decision-making process for outsourcing services, and carrying out the necessary examinations to track the success of the transaction.[20] On the other hand in the exploratory factor analysis section, the analysis of the total variance of economic asset above 2 has been able to determine $11.61 \%$ of the total variance of variables in the overall decision-making framework for outsourcing services in Iranian state-owned hospitals and compared to other effective factors in the outsourcing of services with a factor load of 0.7 and $11.20 / 11$ in one-sample T-test is the most important factor and has a high degree of clarity. After this stage, confirmatory factor analysis was done on the load variables in economic factor. Results also showed confirmation of all variables. So, the economic factor is known as the first factor influencing decision making for outsourcing services in Iranian public hospitals.

\section{Services Characteristics' Factor}

In the exploratory factor analysis, the total analysis of the variance of the service agent with a special value above 2 has managed to fit $62.8 \%$ of the total variance of the variables in the general decision making patterns for outsourcing services in the Iranian public hospitals, which compared to other effective factors in the outsourcing of services with a factor load of $0.6 \%$ and $9.22 \%$ in $\mathrm{T}$ test is the second effective factor and has a high degree of clarity. In this regard, Kavousi et al. titled as "the study of the level of outsourcing tendency based on characteristics of different hospital units from the viewpoint of managers and staff in the selected hospitals of Shiraz University of Medical Sciences", reported in 2011, indicated that consideration of the service feature to be assigned was the most important component of the outsourcing decision-making process.[21] After this stage, the confirmatory factor analysis was done on the variables loaded in the service feature. These results also indicated confirmation of all these variables." investigating the controllability of services for outsourcing" variable has the most weight and "outsourcing services that are not the main activities of the hospital" variable has the least weight in this factor.

\section{Environmental Factor}

In the exploratory factor analysis, the total variance analysis of a specially-valued environmental factor higher than 2 has managed to get 8.07 percent of the total variance of the variables in the general decision making for outsourcing services in the state-owned hospitals of Iran, compared with other effective factors in the provision of services with a factor load of 0.46 and 7.04 in T-test is the third factor and has a great deal of explanation. In this regard, Ghazizadeh Fard and his colleagues conducted a study in 2011 entitled "designing a decision-making model for outsourcing maintenance and repairing activities" and concluded that environmental assessment is one of the main criteria for determining the strategy of IT outsourcing and is in line with the current study.[22] After this step, the confirmatory factor analysis was performed on the variables loaded in the environmental factor. The results also showed that the variables of this validity were confirmed.

\section{Policy Making Factor}

In the exploratory factor analysis, the total variance analysis of the policy-maker factor with special value of more than 2 has managed to fit $7.86 \%$ of the total variance of variables in the overall decision-making for outsourcing services in the state-run hospitals of Iran, compared with other effective factors in the provision of services with a factor load of 0.44 and 7.84 in the sample $\mathrm{T}$ test is the fourth factor and has a high degree of clarity. In a study by Judaki and colleagues in 2015 entitled "outsourcing of hospital services: lessons learned from an experience", it was concluded that effective factors and the main reasons for the failure of outsourcing in the hospitals of the Tehran University of Medical Sciences is lack of proper policy. Therefore, policymaking should be considered as an effective factor in outsourcing decision making in Iranian public hospitals. ${ }^{[10]}$ After this step, the confirmatory factor analysis was performed on the variables loaded in the process of policy-making. The results of the confirmatory factor analysis also indicated that the variables of this validity were confirmed.

\section{Social Factor}

Examining the average score of respondents' opinions about their variables showed that the variable "hospital managers' outlook on outsourcing services" with a factor load of 0.94 and a variable "focus on satisfaction of patients and client to the hospital" with factor load of 0.77 had the highest score among the other variables of the social factor. Tang Xiao (2009) conducted a research on "checking outsourcing in hospitals of Taiwan ", in 165 hospitals using a questionnaire and a statistical method of the exploratory factor analysis and confirmatory factor analysis concluded that effective factors in outsourcing in country hospitals were different in clinical and nonclinical services in Taiwan. Executive factors, financial and human resources factors, and the overall effectiveness of outsourcing in clinical services and the satisfaction of patients and the trainees to the hospital are the effective factors in outsourcing decision-making in non- 
clinical services. Positive results can be achieved if the outsourcing pattern is appropriate.[23]

On the other hand, in the field of exploratory factor analysis, the analysis of the total variance of the speciallyvalued social asset of more than 2 has managed to fit $8.26 \%$ of the total variance of variables in the general decision making for outsourcing services in the state-run hospitals of Iran, compared with other effective factors in the provision of services with a total of 0.42 and 6.56 in T-test is the fifth effective factor, and has a lot of explanation. After this step, a confirmatory factor analysis was performed on the variables loaded in the social activity and the results confirmed it.

\section{Resources Factor}

The average score of respondents' opinions about the variables indicated that the variable "investigating the existence of qualified contractors in the field of outsourcing" had the highest factor load of 0.84 with respect to other variables of factor resources. In a study commissioned by Jamal Bata in 2011 on his doctoral thesis entitled "effective factors on outsourcing in public section" conducted at Aliant in the San Diego city in the United States, the evaluation of suppliers variable, including the quality of services and their number, is considered to be the most important environmental factors in the decision-making process for the outsourcing of services.[24] The research results of the current study confirms this matter as well. Also, in the exploratory factor analysis, the analysis of the total variance of the resource factor with special value above 2 has been effective in comparison with other effective factors in the provision of services with a factor load value of 40.0 and a score of 4.04 in T-test was the sixth factor. After this step, the confirmatory factor analysis was carried out on the variables loaded in the factor of the sources. The results of the confirmatory factor analysis also showed that the variables of this validity were confirmed.

The limitation of the present study is that, its results cannot be generalized to private hospitals.

\section{CONCLUSIONS}

The proposed model for outsourcing decision making in Iranian public hospitals consists of six effective factors (economic, service characteristics, environment, policy, social and resources), which in fact has a comprehensive and multidimensional concept. Therefore, all aspects of its variables should be considered well, such as cost and revenue analysis of outsourcing services, the examination of the controllability of services for outsourcing, the examination of the existence of state laws and regulations on outsourcing, compliance with policies and principles of the hospitals by assigning services, focusing on satisfaction of patients and clients to the hospitals, and examination of the existence of competent contractors in the field of outsourcing can lead to the success of public hospitals in outsourcing services and the organization in this respect can achieve its goals.

\section{REFERENCES}

[1] Tabrizi JS, HaghGoshayie E, Doshmangir L, et al. The barriers to implementation of new public management strategies in Iran's primary health care: a qualitative study. Journal of the Liaquat University of Medical and Health Sciences 2018;17(1):8-17.
[2] Tabrizi JS, HaghGoshayie E, Doshmangir L, et al. New public management in Iran's health complex: a management framework for primary health care system. Primary Health Care Research \& Development 2018;19(3):264-76.

[3] Albreht T. Privatization processes in health care in Europe-a move in the right direction, a 'trendy' option or a step back? The European Journal of Public Health 2009;19(5):448-50.

[4] Kiaei MZ, Moradi R, Hasanpoor E, et al. Hospital managers' perception of recent health care reform in teaching hospitals of Qazvin, Iran. Biotechnology and Health Sciences 2015;2(4): e33196.

[5] Laamanen R, Simonsen-Rehn N, Suominen S, et al. Outsourcing primary health care services-How politicians explain the grounds for their decisions. Health Policy 2008;88(2-3):294-307.

[6] Liu X, Hotchkiss DR, Bose S, et al. Contracting for primary health services: evidence on its effects and a framework for evaluation. Bethesda, MD: The Partners for Health Reformplus Project, Abt Associates Inc., 2004.

[7] Hagen TP, Holom GH, Amayu KN. Outsourcing day surgery to private for-profit hospitals: the price effects of competitive tendering. Health Economics Policy and Law 2018;13(1):50-67.

[8] Tadelis S. The innovative organization: creating value through outsourcing. California Management Review 2007;50(1):261-78.

[9] Rajabzadeh A, Rostamy AAA, Hosseini A. Designing a generic model for outsourcing process in public sector: evidence of Iran. Management Decision 2008;46(4):521-38.

[10] Joudaki H, Heidari M, Geraili B. Outsourcing of hospitals services: lessons learned from the experience. Journal of Health Based Research 2015;1(1):13-23.

[11] Dunnigan MG, Pollock AM. Downsizing of acute inpatient beds associated with private finance initiative: Scotland's case study. BMJ 2003;326(7395):905.

[12] Meisler A. Think globally, act rationally. Workforce Management 2004;83(1):40-6.

[13] Young S, Macinati MS. Health outsourcing/ backsourcing: case studies in the Australian and Italian health sector. Public Management Review 2012;14(6):771-94.

[14] Kremic T, Tukel 0, Rom WO. Outsourcing decision support: a survey of benefits, risks and decision factors. Supply Chain Management: An International Journal 2006;11(6):467-82.

[15] McIvor R. A practical framework for understanding the outsourcing process. Supply Chain Management: An International Journal 2000;5(1):22-36.

[16] Ullman JB, Bentler PM. Structural equation modeling. Handbook of Psychology, Second Edition. Vol. 2. 26 September 2012

[17] Shahbazi M, Kianifar F. An outsourcing expert system for governing organizations. Journal of Information Technology Management 2016;8(3):567-90. 
[18] Karimi H. Outsourcing decision making model for a government organization. Modiriate Novavari 2013;2(2):83-106.

[19] Ikediashi D, Okwuashi O. Significant factors influencing outsourcing decision for facilities management (FM) services: a study on Nigeria's public hospitals. Property Management 2015;33(1):59-82.

[20] Moschuris SJ, Kondylis MN. Outsourcing in public hospitals: a Greek perspective. Journal of Health Organization and Management 2006;20(1):4-14.

[21] Kavousi Z, Setoudehzade F, Kharazmil E, et al. The level of propensity to outsource study: based on hospital services features by managers and staff perspective in hospitals Kavousi Z Abstract: of Shiraz
University of Medical Science 2010. J of Hospital 2012;11(1):9-18.

[22] Ghazizadeh Z, Ahmadvand M, GHolami A. Outsourcing decision making model for a maintenance department in government organization. Police Human Development 2011;39(5):55-72.

[23] Hsiao CT, Pai JY, Chiu H. The study on the outsourcing of Taiwan's hospitals: a questionnaire survey research. BMC Health Services Research 2009;9:78.

[24] Batta J. Factors driving outsourcing in the public sector. A dissertation presented to the Graduate faculty of the school of management. Alliant International University, San Diego. 2011:18. 